\title{
Silver nanoparticle ink technology: state of the art
}

This article was published in the following Dove Press journal:

Nanotechnology, Science and Applications

II January 2016

Number of times this article has been viewed

\section{Krishna Rajan \\ Ignazio Roppolo \\ Annalisa Chiappone \\ Sergio Bocchini \\ Denis Perrone \\ Alessandro Chiolerio \\ Center for Space Human Robotics, Italian Institute of Technology, Turin, Italy}

Correspondence: Alessandro Chiolerio Center for Space Human Robotics, Istituto Italiano di Tecnologia, 21 Corso Trento, Turin 20129, Italy Email alessandro.chiolerio@iit.it
Abstract: Printed electronics will bring to the consumer level great breakthroughs and unique products in the near future, shifting the usual paradigm of electronic devices and circuit boards from hard boxes and rigid sheets into flexible thin layers and bringing disposable electronics, smart tags, and so on. The most promising tool to achieve the target depends upon the availability of nanotechnology-based functional inks. A certain delay in the innovation-transfer process to the market is now being observed. Nevertheless, the most widely diffused product, settled technology, and the highest sales volumes are related to the silver nanoparticle-based ink market, representing the best example of commercial nanotechnology today. This is a compact review on synthesis routes, main properties, and practical applications.

Keywords: silver nanoparticles, surface plasmon resonance, nanocomposites, inks, printed electronics

\section{Introduction}

Silver nanoparticle (NP)-based inks represent the most important commercial nanotechnology-derived product and the most widely studied worldwide. To better clarify the motivation of this review, we should therefore focus on the three points highlighted: the raw material (Ag), the morphology it takes (NPs), and the compound through which it is used in practical applications (ink).

Let us start with silver. Why Ag in place of other raw materials? Because it is a noble metal, featuring undisputed advantages in terms of electrical conductivity, resistance to oxidation, and providing interesting plasmonic and antibacterial properties, as we will see further in the text. The topic is far too wide to be synthesized in a single sentence, and there is no single source from which to extract information regarding the different materials that could be used to prepare conductive inks ( $\mathrm{Au},{ }^{1} \mathrm{Cu},{ }^{2}$ brass, ${ }^{3}$ nickel, ${ }^{4}$ $\mathrm{Cr},{ }^{5} \mathrm{Fe},{ }^{6} \mathrm{Ti},{ }^{7}$ intrinsically conductive polymers, ${ }^{8}$ thin conductive oxides, ${ }^{9}$ carbon-based materials). ${ }^{10}$ It is difficult to imagine a future without the use of $\mathrm{Ag}$, at least for certain critical systems that cannot lose efficiency. The market share will be reduced in favor of other nanoengineered, less expensive materials, but it is not possible to avoid the use of metals to transport electricity without losses.

Then, why NPs? The most important feature is connected with their scale, bringing surface tension and ionic forces to that level of importance that allows a play against gravity, giving stability to a suspension. But many other interesting phenomena occur: collective electron resonances, the so-called plasma waves enabling surface plasmon resonance (SPR), and interactions with the electromagnetic field; ${ }^{11,12}$ a huge enhancement of diffusivity of the surface atoms, enabling "melting" (sintering) at extremely low temperatures, ${ }^{13}$ 
and so on. In a world where nanoengineered materials could have broad application, from the consumer electronics market, building industry, pharmaceutical and cosmetic products, to food and the environment, we can easily imagine that the role of NP synthesis and modification activities will be huge.

Finally, why inks? Inks and writing/printing technology date back to the 23 rd century BC (almost 4,500 years ago), presumably being invented in the People's Republic of China by Tien Chu under the empire of Huang Ti. ${ }^{14}$ Probably the first nanotechnology ever discovered and applied was that of black ink based on carbon black and bone black, containing fullerenes and a wide variety of aromatic small molecules. Today, printing technology has expanded its horizon toward the realization of electron devices on any substrate, according to two main approaches: 1) analog printing, involving the use of linear/rotary machines that are able to realize multiple copies of the same pattern at a rather high speed (serigraphy, gravure, offset, flexography), involving generally microstructured inks; and 2) digital printing, where raster machines realize at rather slow speed a single copy of a pattern that could be changed simply working at the software level (inkjet printing, 3-D printing), involving nanostructured inks. In Figure 1, an example of a complex circuit realized on an unconventional substrate

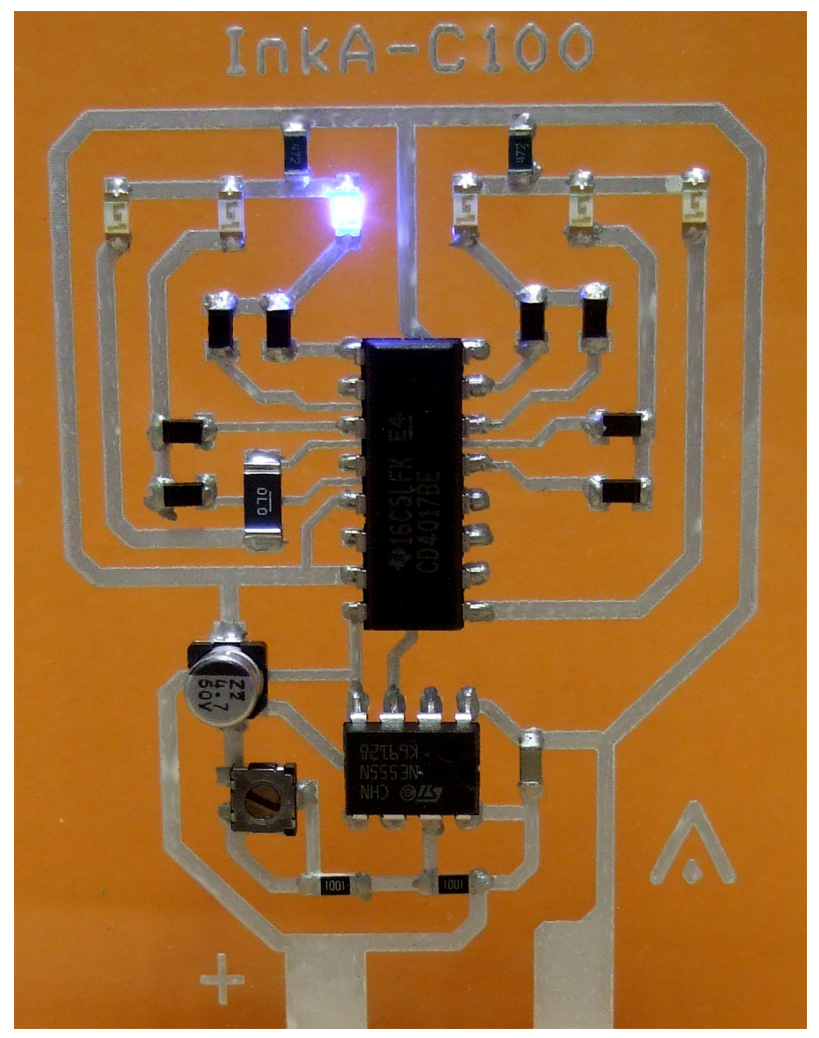

Figure I Silver nanocomposite ink after sintering and resin bonding of discrete electronic components.

Notes: Printed on borosilicate glass. Image courtesy of Politronica Inkjet Printing SRL. (borosilicate glass) is shown: thanks to a silver NP-based ink submitted to a sintering treatment and to a bonding phase, it was possible to join the conductive track with discrete traditional components. This is the present cutting-edge level of research. What will be there in the future? We think that once the processes and techniques to produce pure and controlled $\mathrm{Ag}$ NPs are settled, more complicated systems involving multimaterial processing could be studied, producing multifunctional, adaptable, and adaptive smart materials. It could be nice to see "futu-retro" technological objects, based on principles as old as 4,500 years but able to realize those functions that are at the basis of our modern "e-society".

Now that the application domain is clear, to come back to the first question we asked: why is silver so important among nanostructured inks? Silver has optimal electron conductivity and a lower affinity for oxygen if compared to copper, it is 25 times more abundant than gold on Earth's crust, and hence is less expensive. Silver NPs and nanocomposites (NCs) possess interesting electrical, optical, and chemical properties used in catalysis, surface-enhanced Raman spectroscopy (SERS), nanoelectronics, photonics, and biological and physical sensing. ${ }^{15-21}$ Shape and dimension of Ag NPs are easily controllable, resulting in tunable properties. ${ }^{22}$ We will see how silver NP inks are produced and applied in the following sections.

\section{Synthesis methods}

Nanocrystals can be fabricated using two different approaches (Figure 2): the first, known as "top-down", utilizes physical methods to reduce crystal size, while the other, the "bottom-up" approach, is based mainly on solutionphase chemistry and also named wet chemistry. ${ }^{23}$ Physical methods usually allow the production of a large quantity of nanocrystals, but is very difficult to control geometry or have a uniform size. In contrast, wet chemical synthesis allows the synthesis of nanocrystals with controlled particle size. Furthermore, as we will see, several nanocrystal shapes can be synthesized by varying the reaction conditions. In the case of inks, the control is really important, because of the dependency of specific properties on the size and shape of the nanocrystal. For these reasons, wet chemical synthesis is generally preferred. In this context, a wide variety of wetsynthesis techniques have been proposed to produce metal nanocrystals and in particular Ag nanocrystals, including chemical reduction, ${ }^{24-26}$ electrochemical and photochemical reduction, ${ }^{27-29}$ sonochemistry, and heat evaporation. ${ }^{30,31}$

The main route involves the bottom-up synthesis, starting from the silver salts and leading to the final nanocrystals. Three distinct stages can be roughly recognized (Figure 3).32,33 


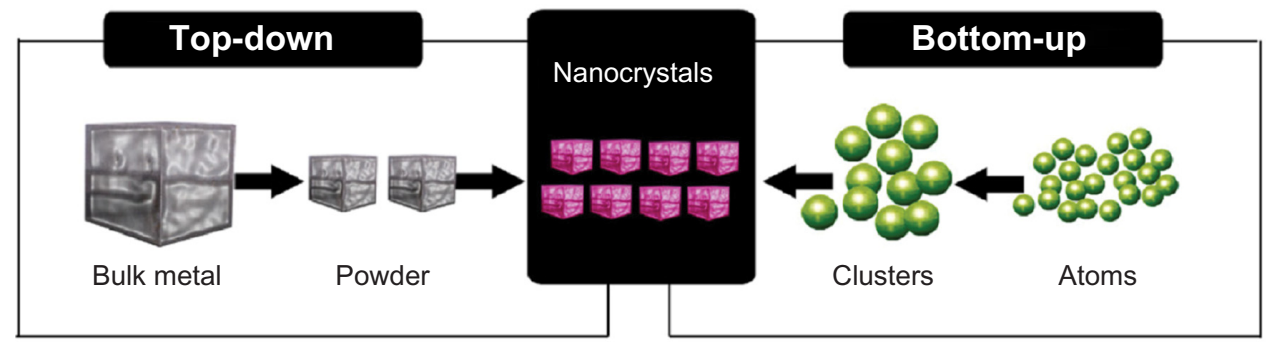

Figure 2 Top-down and bottom-up approaches to the synthesis of nanocrystals.

Notes: Adapted from “Ion Exchange Technologies", book edited by Ayben Kilislioğlu, ISBN 978-953-5I-0836-8, Published: November 7, 20I2 under CC BY 3.0 license. (C) Domènech et al. ${ }^{32}$

Nucleation, the clustering of few atoms and/or ions, is the first stage of any crystallization process. ${ }^{34}$ In the second step, a seed is formed through atom-by-atom addition to the initial nuclei. In the final step, the seeds grow mainly in size while the shape is largely determined by the structure of the seed.

NP properties, such as catalytic, optical, magnetic, and electronic, have been demonstrated to be size- and shapesensitive ${ }^{35-38}$ Nowadays, research efforts are put into not only controlling size and suspension stability but also developing unconventional crystal geometry, eg, synthesizing well-defined anisotropic and/or organized nanostructures. For ink production, usually it is easier to use wet synthesis, because the final NPs are employed in suspension, and thus only bottom-up solution-phase synthesis methods will be discussed.

\section{Bottom-up self-assembly approach}

Bottom-up solution-phase synthesis of metal nanocrystals starts from zerovalent metal compounds or salts dissolved in a solvent. In particular for silver, these precursors are in the +1 oxidation state $\left(\mathrm{Ag}^{+}\right)$, and thus, during the reaction,

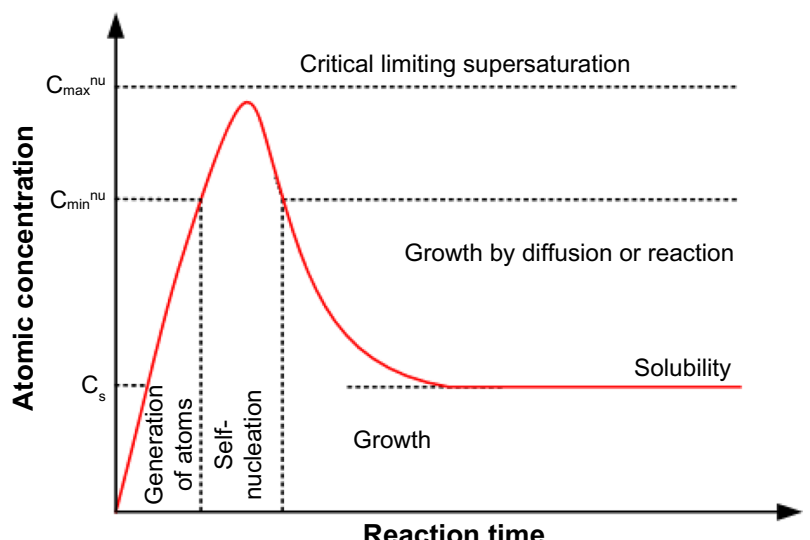

Figure 3 Plot of atomic concentration against time, illustrating the generation of atoms, nucleation, and subsequent growth.

Notes: Reprinted with permission from LaMer VK, Dinegar RH. Theory, production and mechanism of formation of monodispersed hydrosols. J Am Chem Soc. 1950;72(II):4847-4854. Copyright 1950 American Chemical Society. ${ }^{35}$
$\mathrm{Ag}^{0}$ atoms are produced as metal nanocrystal building blocks. Two synthetic pathways are at present under discussion. The first possibility consists in reducing the precursor compound into zerovalent atoms, which then aggregate into the nuclei and grow into nanocrystals. In the second possible reaction pathway, the unreduced metal species associate with nuclei and then are reduced to zerovalent metal species. ${ }^{33}$

Generally, the mechanism depends on reaction conditions: higher precursor concentrations and mild reducing agents shift the reaction from the first to the second pathway. A low reduction rate and high concentration of metal ions prevent the complete reduction into the zerovalent state. A nanosize cluster surface results thus positively charged, and could be stabilized by the capping effect of ionic species, such as halide or carboxylic anions, as well as solvent molecules or polymeric species. ${ }^{33}$

Kinetic control is achieved when the crystal formation is directed by a moderate driving force, thus under conditions far away from the thermodynamic equilibrium. Under kinetically controlled synthesis, the reaction proceeds considerably more slowly than under normal conditions, thus, slowing down the precursor decomposition or reduction. ${ }^{39}$

Silver salts are usually insoluble in any solvent, and thus the most used precursor for $\mathrm{Ag}$ nanocrystal production is silver nitrate $\left(\mathrm{AgNO}_{3}\right)$, which has good solubility in polar solvents. The preferential seed shapes from silver salt reduction are icosahedral and decahedral, thermodynamically favored from the face-centered cubic lattice of metallic silver.

\section{Surfactant-assisted synthesis}

Nanocrystal shape can be controlled by the addition of capping agents (Figure 4). Surfactants, polymers, biomolecules, small organic molecules, and metal ions or atoms can be used as capping agents. They operate mainly by being adsorbed on a specific crystal plane and thus reduce surface free energy, changing the relative growth rate and inducing growth on the uncapped surfaces. Despite their importance in controlling 


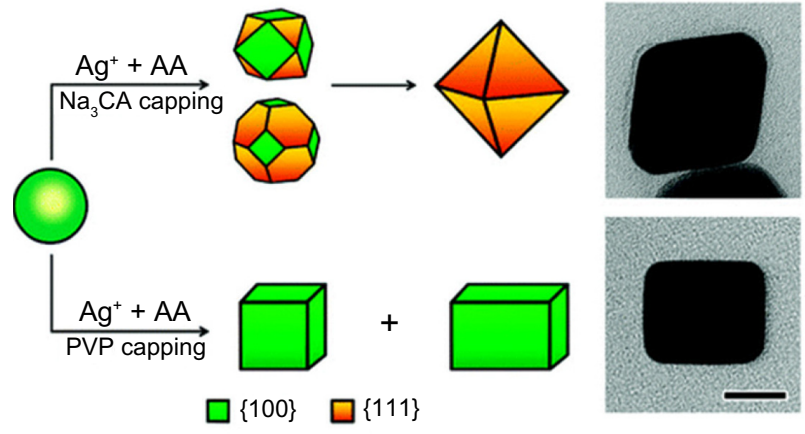

Figure 4 Role of a capping agent in controlling the evolution of $\mathrm{Ag}$ seeds into nanocrystals with different shapes.

Notes: Starting with single-crystal seeds, it is possible to selectively obtain $\mathrm{Ag}$ octahedrons enclosed by $\{\mathrm{III}\}$ facets by adding sodium citrate $\left(\mathrm{Na}_{3} \mathrm{CA}\right)$ and nanocubes/nanobars enclosed by $\{100\}$ facets by adding polyvinylpyrrolidone (PVP). Reprinted with permission from Zeng J, Zheng Y, Rycenga M, et al. Controlling the shapes of silver nanocrystals with different capping agents. J Am Chem Soc. 20I0;132(25):8552-8553. Copyright 2010 American Chemical Society. ${ }^{45}$

Abbreviation: AA, L-ascorbic acid.

shape, their mechanism of action is still not completely understood, and thus knowledge on the produced shapes is mainly obtained by trial-and-error attempts. ${ }^{40}$

Capping agents are used according to two different approaches. In the first approach, the seeds are grown directly into the solution and the capping agents used to orient the addition of the metal atoms on the surface, where the capping agents are either weakly or not bonded. In the second approach, preformed seeds in which capping agents orient the growth are added in the synthesis solution.

The most used capping agents for Ag NPs are polyvinylpyrrolidone (PVP), a polymeric capping agent, and bromine anions. Both the agents tend to be selectively adsorbed onto the $\{100\}$ facets of Ag nanocrystals, driving the addition of new $\mathrm{Ag}$ atoms to other crystal facets. ${ }^{41,42}$ Both capping agents induce the formation of nanocubes, rectangular nanobars, and octagonal nanorods. Bromine ions are much smaller than PVP, and thus the crystals obtained with this capping agent are usually smaller than $25 \mathrm{~nm}$ in size. By slowing the reduction rate, thus using mild reducing agents, such as ascorbic acid, it is also possible to obtain $\mathrm{Ag}$ nanoplates..$^{43,44,45}$

\section{UV-induced synthesis of silver NPs}

Since the 19th century, silver salts, eg, silver halides, have been used as photosensitive compounds for photography applications. In fact, their light exposure leads to the generation of metallic particles that were used in photography emulsion. ${ }^{46}$ Therefore, light radiation is a common way to synthesize silver colloids and NPs.
Photoreduction occurs when photogenerated free electrons react with $\mathrm{Ag}^{+}$ions, forming the corresponding $\mathrm{Ag}^{0}$ metal atom. $\mathrm{Ag}^{+}$ions in solution and efficient photogeneration are the main issues to control in order to have an effective production of Ag NPs.

By changing precursors and electron donors, it is possible to control both the dimension and the shape of the NPs synthesized. One of the first syntheses of silver NPs in aqueous and alcohol solution was performed by Hada et al in the 1970s by ultraviolet (UV)-induced photoreduction using the photooxidation of water and alcohols under a deep-UV irradiation..$^{47}$ Nowadays, the most common used electron donors are aromatic ketones: they undergo cleavage under UV irradiation, producing radicals that induce reduction of silver. ${ }^{48-51}$ Other molecules reported as photoreducing agents or other parameters have been involved in the reduction process, such as the use of acrylic monomers, ${ }^{52}$ sodium citrate to control the $\mathrm{pH},{ }^{53}$ reaction performed in nonaqueous media or even applying magnetic fields. ${ }^{54,55}$

Electrons can be also photogenerated by photoactive semiconductors: under UV irradiation, they are able to promote a free electron that can reduce $\mathrm{Ag}^{+}$; usually, in this case the redox reaction is balanced by oxidation of the solvent, mostly water. The most investigated materials have been titanium dioxide and zinc oxide..$^{56-59}$

\section{Ag NP structural, morphological, and functional properties}

As reported in the previous section, in order to exploit the potential of metal NPs fully and to provide effective strategies to tune electronic and optical properties of materials, the control of size and morphology of nanostructures are of fundamental and technological interest. ${ }^{60}$ Noble metal NPs $(\mathrm{Ag}, \mathrm{Au}, \mathrm{Pt}$ ) are extremely interesting because of their unique properties, and among them $\mathrm{Ag}$ possess the highest electrical and thermal conductivity, along with other properties, which promote its extensive use in a wide range of applications. Nowadays, Ag NPs are largely used to produce conductive tracks with inkjet printing, thanks to the high conductivity and thermal stability of such materials. ${ }^{61-63}$

Conductive inks normally are aqueous or organic solvent dispersions of silver NPs that are stabilized by surfactants and polymers that undergo printing, a drying step, and at the end a sintering process that is commonly achieved by heating the printed substrates to a temperature usually higher than $200^{\circ} \mathrm{C}$. Alternatively, more unconventional techniques, such as microwave ${ }^{64}$ laser radiation, ${ }^{65}$ flash sintering, ${ }^{66}$ plasma, ${ }^{67}$ and electrical- or chemical-induced sintering, can be pursued. ${ }^{68,69}$ 
Sintering at $200^{\circ} \mathrm{C}$ is much below the melting point of silver $\left(960^{\circ} \mathrm{C}\right)$, and it can be attributed to the enhanced surface diffusion of atoms and to surface premelting; therefore, even in the sintering process, the dimension and shape of Ag NPs are one of the first properties to be investigated. ${ }^{70}$

Ag NPs used for inks generally have spherical shape with diameters ranging from 5 to approximately $100 \mathrm{~nm}$ with narrow dimensional distribution. Several works are presented in the literature using such NPs. Fuller et al described an inkjet ink based on colloidal silver NPs of spherical shape with a diameter of approximately $5-7 \mathrm{~nm}$ dispersed $10 \mathrm{wt} \%$ in $\alpha$-terpineol, which was sintered at $300^{\circ} \mathrm{C}$ on a hot plate, giving conductive lines of $80 \mu \mathrm{m}$ and presenting a resistivity of $3 \mu \Omega / \mathrm{cm}^{.11}$

Lee et al proposed a conducting ink composed of silver NPs with diameter around $50 \mathrm{~nm}$ dispersed in a water-anddiethylene glycol cosolvent system. Continuous and smooth lines of $130 \mu \mathrm{m}$ width were printed, and after baking at $260^{\circ} \mathrm{C}$ for 3 minutes, these lines exhibited a resistivity of $16 \mu \Omega / \mathrm{cm}^{72}$

Chiolerio et al explored the effects of NP-diameter distribution and composition of Ag NP-based inks for the realization of inkjet-printed microwave circuits. ${ }^{73}$ Different NP sizes were measured by numerical analysis of field-emission scanning electron microscopy images, and electrical measurements after annealing gave a surface resistance ranging from 19.4 up to $30 \mathrm{~m} \Omega / \square$, as specified in Table 1. The best-performing composition was found to be the one containing an added copolymer, and fieldemission scanning electron microscopy analysis showed a peculiar NC structure with a percolating network of NP agglomerates, with an extremely low density of metal into the polymeric network.
Different kinds of NP shapes are also presented for the fabrication of conductive inks, such as silver nanowires, which have huge potential applicability in transparent electrodes, but can give rise to problems, such as clogging of the printhead nozzles..$^{74,75}$ In one of the most recent works, Finn et $\mathrm{al}^{75}$ presented the controlled deposition of networks of silver nanowires (average diameter of $55 \mathrm{~nm}$ and an average length of $8.1 \mu \mathrm{m}$ ) in well-defined patterns by inkjet printing from an optimized isopropyl alcohol-diethylene glycol dispersion. The resultant networks, after an evaporation/ annealing process at $110^{\circ} \mathrm{C}$, presented sheet resistance of $8 \Omega / \square$ and conductivity of $105 \mathrm{~S} / \mathrm{m}$, achieved for line widths of 1-10 $\mathrm{mm}$ and network thicknesses of $0.5-2 \mu \mathrm{m}$ deposited from $\sim 10-20$ passes. In this case, the thinner networks showed semitransparency.

In 2012, Tung et al proposed shape-controlled synthesis of Ag NPs by X-ray irradiation for inkjet printing with which various shapes, including spheroidal, prism, rod, and multifaceted NPs, were produced by varying the initial concentration of PVP and $\mathrm{AgNO}_{3}{ }^{60}$ It was demonstrated that at an optimized reagent ratio, a mixture of high-aspectratio rods (tunable to $\sim 50$ ), and spheroidal particles could be obtained, and such a mixture was proven to have a melting point and dispersive properties suited to inkjet printing of conductive tracks. The resistivity of the printed lines decreased to $77.7 \mu \Omega / \mathrm{cm}$ and $33.1 \mu \Omega / \mathrm{cm}$ after heating to $200^{\circ} \mathrm{C}$ and $350^{\circ} \mathrm{C}$. Nanoplatelets were also proposed for ink applications ${ }^{76,77}$ allowing the formation of tracks with relatively low resistivity $(7.4 \mu \Omega / \mathrm{cm}$ compared to $30 \mu \Omega / \mathrm{cm}$ of a similar track made by NPs), with good stability after external repetitive bending stress (Figure 5). The authors attributed the electrical resistivity and mechanical stability values to the dense microstructure resulting from the NP shape. It was

Table I Collection of relevant data for inks according to UV-vis measurements, FESEM analysis, and electrical measurements after annealing

\begin{tabular}{lllllll}
\hline Ink name & $\begin{array}{l}\text { NP diameter main } \\
\text { mode } \mathbf{x} \pm \mathbf{s}(\mathbf{n m})^{\mathbf{a}}\end{array}$ & $\begin{array}{l}\text { NP diameter main } \\
\mathbf{m o d e} \mathbf{2} \mathbf{x} \mathbf{s}(\mathbf{n m})^{\mathbf{a}}\end{array}$ & $\begin{array}{l}\text { Main peak } \mathbf{x} \pm \mathbf{w} \\
(\mathbf{n m})^{\mathbf{b}}\end{array}$ & $\begin{array}{l}\text { Secondary peak } \\
\mathbf{x} \pm \mathbf{w}(\mathbf{n m})^{\mathbf{b}}\end{array}$ & $\begin{array}{l}\text { Tertiary peak } \\
\mathbf{x} \pm \mathbf{w}(\mathbf{n m})^{\mathbf{b}}\end{array}$ & $\begin{array}{l}\text { Surface resistance } \\
(\mathbf{m} \Omega / \square)\end{array}$ \\
\hline C10 (46) & $10 \pm 5$ & NA & $409.7 \pm 48.9$ & NA & NA & 30.0 \\
C10 (47) & $15 \pm 5$ & $100 \pm 50$ & $400.1 \pm 31.0$ & $365.9 \pm 43.5$ & NA & 30.0 \\
C10 (52) & $6 \pm 2$ & $15 \pm 5$ & $420.5 \pm 65.7$ & NA & NA & 30.0 \\
C20 (48) & $25 \pm 15$ & NA & $439.2 \pm 77.4$ & $555.3 \pm 193.2$ & $365.9 \pm 43.5$ & 19.4 \\
C30 (49) & $6 \pm 2$ & $40 \pm 10$ & $469.7 \pm 115.0$ & NA & NA & 30.0 \\
C40 (4I) & $12 \pm 2$ & $100 \pm 50$ & $441.0 \pm 285.1$ & NA & NA & 22.4 \\
C40 (5I) & $12 \pm 2$ & $100 \pm 10$ & $470.0 \pm 177.6$ & NA & NA & 22.4 \\
C100 (7) & $12 \pm 2$ & NA & NA & NA & 30.4 \\
\hline
\end{tabular}

Notes: a As determined from numerical analysis of FESEM images (median \pm standard deviation); bas determined from multi-Gaussian fit to UV-vis spectra (peak position \pm peak width). Reprinted from Microelectronic Engineering, Volume 97 edition 9, Chiolerio A, Cotto M, Pandolfi P, et al, Ag nanoparticle-based inkjet printed planar transmission lines for RF and microwave applications: considerations on ink composition, nanoparticle size distribution and sintering time, Pages 8-15, Copyright 20I2, with permission from Elsevier. ${ }^{73}$

Abbreviations: UV-vis, ultraviolet-visible; FESEM, field-emission scanning electron microscopy; NP, nanoparticle; NA, not applicable. 

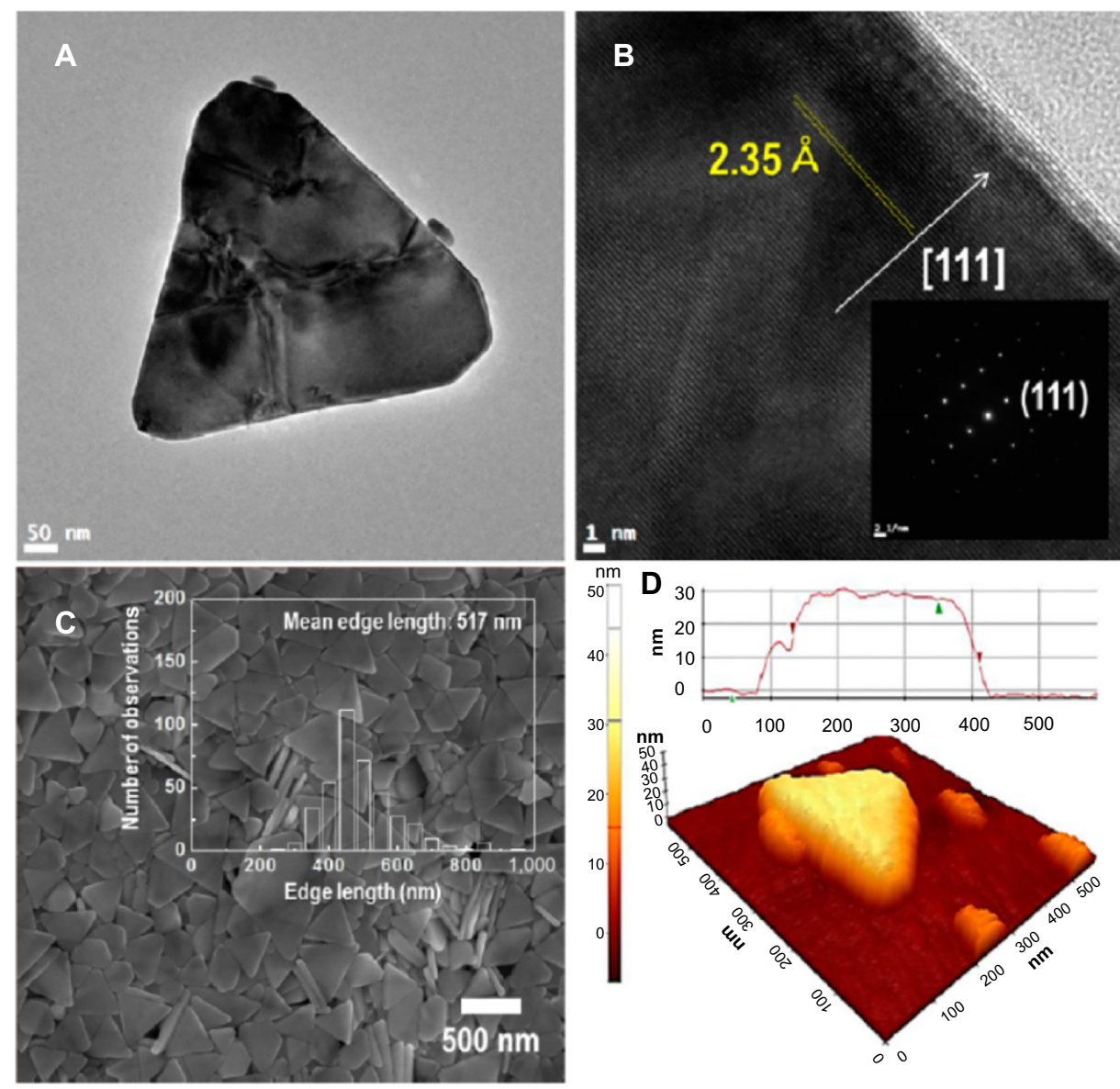

Figure 5 TEM and AFM of silver nanoplatelets.

Notes: (A) TEM image, (B) high-resolution TEM images with selected-area electron-diffraction patterns (inset), (C) FESEM image with edge-length distribution (inset graph), and (D) AFM image and thickness profile of silver nanoplatelets synthesized by the solvothermal method. Reprinted with permission from Lee YI, Kim S, Jung SB, Myung NV, Choa YH. Enhanced electrical and mechanical properties of silver nanoplatelet-based conductive features direct printed on a flexible substrate. ACS Appl Mater Interfaces. 2013;5(I3):5908-59I3. Copyright 2013 American Chemical Society. ${ }^{76}$

Abbreviations: TEM, transmission electron microscopy; FESEM, field-emission scanning electron microscopy; AFM, atomic force microscopy.

also demonstrated that the pulsed-laser sintering was able to control the shape of the Ag NPs, avoiding the typical "coffee stain" effect and realizing patterned lines with conductivity very close to that of $\mathrm{Ag}$ bulk. ${ }^{78}$

An alternative use of Ag inks is related to NP optical properties. It is well known that Ag NPs possess a characteristic plasmon resonance in the visible range that could be controlled by properly tuning their dimensions, number, and relative distance. ${ }^{79-82}$ This property could be exploited for producing optical waveguides..$^{83}$ Another property well exploited in the literature is the high transparency that could be obtained from thin films (over 95\%) that is necessary in some applications. ${ }^{84,85}$ Also, homogeneous films of Ag NPs show high reflectivity in the visible range; this property was well exploited in order to produce reflective electrodes for solar cells, enhancing considerably solar cell performances. ${ }^{86,87}$

\section{Applications}

The following sections deal with the most important applications of Ag NP-based inks.

\section{Surface-enhanced Raman spectroscopy}

SPR is an effect commonly seen in metals where free electrons collectively oscillate in phase with the incident light, ${ }^{88}$ driven by the alternating electric field when irradiated by light of proper wavelength. SPR enables an effective scattering and absorption of light under a resonant condition. For example, this gives to metal colloids, like Ag, their brilliant colors. Concurrently, surface charges are polarized under the excitation of incoming light. In the case of metal NPs, the generated charges cannot propagate as a wave along a flat surface as in bulk metals, but are confined to and concentrated on the NP surface, and thus, this phenomenon is called localized SPR (LSPR) ${ }^{88}$ 
In these conditions, if organic molecules are adsorbed on the surface of metal NPs, LSPR leads to intense local electric fields within a few nanometers from the particle surface, and thus can be used for the enhancement of the Raman-scattering cross sections of molecules. This would provide an enhanced "fingerprint" spectrum of the molecule, rich in chemical information. This technique is widely known as SERS, and was first demonstrated by Fleischmann and Van Duyne in the 1970s. ${ }^{89-92}$

It is also known that not only the nanosize dimensions but also the shape of a nanocrystal affects its interaction with electromagnetic waves. Therefore, the intensity and position of LSPR peaks can be fine-tuned by shape control, and a significant Raman-signal enhancement can be achieved by simply selecting nanocrystals with an appropriate shape. The detection of diluted analytes is possible by the signal enhancement of organic molecules. Therefore, the sensitivity of SERS can be greatly enhanced by many orders of magnitude by tailoring the shape of Ag nanocrystals and thus their plasmonic features, ${ }^{93,94} \mathrm{ie}$, LSPR. ${ }^{95,96}$ Particularly, branched silver nanocrystals with tips, such as stars, flowers, and dendrites, have attracted increasing interest for their application in SERS, due to the enhanced plasmonic features. ${ }^{97}$

\section{$\mathrm{Ag}$ polymer $\mathrm{NCs}$ by direct embedding of silver NPs in polymers}

\section{Conductive NCs}

Embedding highly conductive nanofillers in polymer is a common strategy for producing conductive polymer NCs. One of the common strategies used in order to characterize a noble metal-polymer composite is to evaluate its electrical resistivity. Many works have been reported in literature in this regard.

Silver conductive NCs were synthesized by embedding silver NPs of different shapes in diverse matrices, such as high-density polyethylene, ${ }^{98}$ polymethyl methacrylate, ${ }^{99}$ polyvinyl alcohol, ${ }^{100,101}$ bisphenol $\mathrm{F}$ diglycidyl ether, ${ }^{102}$ polyvinylidene difluoride, and polydimethylsiloxane, ${ }^{103}$ but also in inks and conductive polymers, such as poly $(3,4-$ ethylenedioxythiophene). ${ }^{104}$

\section{Sensors}

Taking advantage of the electrical conductivity of silverbased NCs that arise upon mechanical stress variation, different pressure and tactile sensors have been produced. These NCs were recently reviewed by Nambiar and Yeow. ${ }^{105}$

\section{In situ synthesized Ag NCs}

Homogeneous dispersion of metallic NPs in polymer matrices remains a critical issue for $\mathrm{NC}$ preparation, due to their high surface energy. A common strategy in order to disperse NPs in polymeric matrices is to functionalize the surface of the NPs. An alternate way developed over the last few years envisages the direct dispersion of silver photosensitive precursors in photocurable monomers (often using a cosolvent) followed by UV irradiation, which results in the formation of a polymeric network and in the formation of metal NPs. In literature, several studies have used silver hexafluoroantimonate (in acrylates, ${ }^{106-108}$ epoxies, ${ }^{109,110}$ thiol-ene, ${ }^{111}$ and divinyl ether systems $),{ }^{12}$ and also in engineered structures, ${ }^{113}$ using silver nitrate for synthesizing silver NCs. ${ }^{114}$

\section{Unconventional Ag NCs}

In this section, some innovative strategies for the synthesis of silver NCs are presented in order to illustrate possible future trends in this field. The first strategy concerns the control of the shape of NPs in the solid-bulk phase. Trandafilovic et al reported about the synthesis of silver nanoplates in polyampholyte copolymers. ${ }^{115}$

\section{Tunneling conductive fillers in piezoresistive composites}

Piezoresistive composite materials have recently found interesting applications in the fields of microsensors, ${ }^{116,117}$ electromechanical devices, circuit breakers, ${ }^{118}$ touchsensitive screens, and tactile sensors for robotics. ${ }^{119}$ With respect to commercially available devices, these composite systems can provide cheaper, faster, and more accurate alternatives. By varying the nature and morphology of the type of polymeric matrix and the conductive particles that are used as functional fillers, ${ }^{120}$ the properties of these composite materials can be tuned. The percolation effect can be used to explain the conduction mechanism in the case of contact between particles, ${ }^{121,122}$ and the tunneling mechanism where each conductive particle is separated from the others by a thin layer of insulating polymer, which represents the tunneling barrier. ${ }^{123,124}$ In the case of piezoresistive composites, which are based on the tunneling mechanism, a huge change in electrical conductivity is caused, due to an external load-induced deformation. ${ }^{125,126}$ The applied mechanical strain induces a decrease in polymer thickness between the particles, thus reducing the tunneling barrier. In this way, a large reduction in bulk electrical resistance takes place by an increased probability of tunneling.

Silver nanostructures have also been studied and employed as conductive fillers for functional sensing composites. Recently, Hong et al ${ }^{127}$ investigated the electrical 
and thermal conductivities of a silver flake-thermosetting polymer composite. The influence of silver-flake size, distribution, and filler loading on the electrical volume resistivity and thermal conductivity of the composite was studied in detail by the authors.

\section{Ag-based inks for inkjet-printing flexible electronics}

Concentrated silver (Figure 6) NPs are well-recognized materials with potential applications in the field of printing technology. These are used for the preparation of metallic structures on various substrates, because of their high electrical conductivity and resistance to oxidation. Such inks should meet some important requirements: for instance, they should not dry out and clog when in the printhead, they should have good adhesion to the substrate with limited coffee-ring

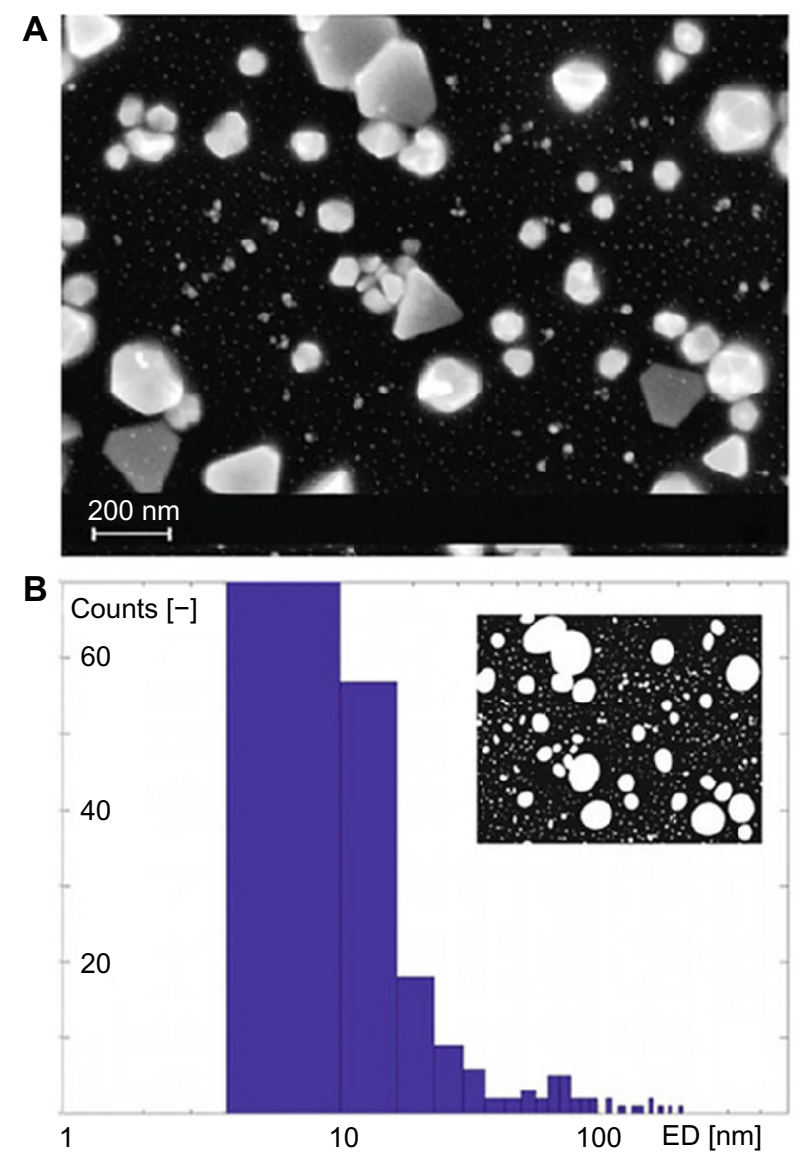

Figure 6 FESEM image of a water-based Ag nanoink.

Notes: Deposited on an Si wafer (A); numerically extracted size distribution of nanoparticle population (B). Reprinted from Microelectronic Engineering, Volume 97 edition 9, Chiolerio A, Cotto M, Pandolfi P, et al, Ag nanoparticle-based inkjet printed planar transmission lines for RF and microwave applications: considerations on ink composition, nanoparticle size distribution and sintering time, Pages 8-15, Copyright 2012, with permission from Elsevier. ${ }^{73}$

Abbreviations: FESEM, field-emission scanning electron microscopy; ED, equivalent diameter. effect and reduced particle aggregation, and they should be characterized by suitable viscosity and surface tension, as they determine drop size, drop-placement accuracy, satellite formation, and wetting of the substrate. ${ }^{128}$ These requirements are very well met by Ag NP-based inks.

In this regard, there are several approaches to formulate Ag-based inks for piezoelectric and thermal inkjet printing that can produce low resistivity and high-resolution conductive traces on different substrates. ${ }^{73,129,130}$ The primary components for all conductive inks include an appropriate amount of highly conductive metal precursor, such as Ag, $\mathrm{Cu}$, and $\mathrm{Au}$ NPs, and a carrier vehicle. The majority of the inks are water-based, and water used in these inks should be very pure so as to limit contaminants. Inks may also contain other additives, such as humectants, binders, surfactants, and bactericides/fungicides. The additives are typically a small percentage with respect to the composition of the ink, and are used to tune ink properties or to add specific properties, thus increasing its performance. Compatibility of the selected ink with a particular inkjet system chosen for deposition is very important, as this influences the interaction among NPs. ${ }^{131}$

In order to avoid precipitation and agglomeration of metal NPs in colloidal inks, dispersants are added to the formulation, which helps to stabilize metal colloids. This helps to increase the loading rate of NPs, thus leading to the synthesis of conductive inks of higher quality. Surfactants and polymers are added to inks in order to interact with the surface of NPs and to form a coating of variable composition and thickness. The resulting modified particle surfaces either attract or repel each other, leading to flocculation or stabilization, respectively. Apart from these, humectants, including alcohols and glycols, are also added to the ink as an additional vehicle or carrier for metal NPs. These control the evaporation of the ink, and help in the reduction of the coffee-ring effect. ${ }^{132}$

Ink transfer to different substrates is facilitated with the help of binder components, which are typically resins that will remain on the substrate or surface along with the NPs. Another important ingredient used in conductive inks is the surfactant, molecules that contain both a hydrophilic and a hydrophobic portion. The main role of a surfactant is to adjust the surface tension of the resultant ink. The addition of a surfactant to a water-based ink will have the result of drastically lowering the surface tension, due to the orientation effects at interfaces caused by the hydrophilic and hydrophobic portions of the surfactant. High surface tension of the ink leads to reduced wettability of the cartridge as well as the substrate, resulting in poor reproduction of the geometry. ${ }^{127}$ Growth of bacteria and fungi are common in inks, and this can be avoided by the 
addition of biocides and fungicides, though with Ag conductive inks it is not necessary, since Ag NPs themselves have antibacterial properties.

One of the most important parameters of an ink is its viscosity. In order to adjust the viscosity to the desired value, a polymeric thickening agent can be used (eg, polyvinyl alcohol). ${ }^{133}$ In the case of piezoelectric printheads, the ink viscosity should be in the range of 5-20 cP, while thermal printheads require a viscosity ranging from 1 to $5 \mathrm{cP}$.

After inkjet printing of a metal NP-based ink, a sintering process has to be performed in order to form a conductive printed pattern. Sintering is the process of welding particles together at temperatures below the corresponding bulk-metal melting point, which involves surface-diffusion phenomena rather than phase change between the solid and the liquid. The conventional approach to sintering metal NPs is heating either with a hot plate or an oven driven by conduction/ convection mechanisms (thermal sintering). ${ }^{72}$

In addition to thermal sintering, at present some emerging sintering techniques are being studied and used, such as laserinduced sintering, ${ }^{134}$ flash sintering (photonic sintering), ${ }^{66}$ microwave oven sintering, ${ }^{64}$ and low-pressure Ar plasma sintering (plasma sintering). ${ }^{67}$ Sintering can also be obtained by the addition of a positively charged polyelectrolyte, such as polydiallyldimethylammonium chloride, which promotes the coalescence of the NPs due to a decrease in their zeta potential (chemical sintering). ${ }^{135}$

Thermal sintering has been discussed by several authors as a method to optimize the quality of printed silver ink lines, in view of their use as electrodes. A critical drying temperature was found to determine an optimal profile of the printed line, thus also improving the electrical properties of the electrode. In these studies, the authors also considered the effect of other factors on the properties of the printed electrodes, such as drop volume, ${ }^{136}$ different substrates, and thicknesses of the printed layers. ${ }^{137,138}$

The use of inkjet-printed electrodes is important in view of their integration in complex electronic circuits like organic thin-film transistors. ${ }^{139}$ In recent years, silver NP-based inks have found a wide range of applications, such as thin-film photovoltaic solar cells, ${ }^{140}$ screen printing (which can replace some printed circuitboard interconnections), ${ }^{141}$ membrane touch switches, touch screens, ${ }^{140}$ automotive sensors, ${ }^{142,143}$ and automatic radio-frequency identification. ${ }^{144}$

\section{Conclusion}

Among metal nanostructures, Ag-based ones are the most diffused (and discussed) from both an academic and commercial point of view. This leads to the formulation of a wide range of nanostructured inks for a huge range of applications. Such inks are mainly employed in the field of printed electronics, promising to bring to the consumer great breakthroughs and unique products, shifting the usual paradigm of electronic devices and circuit boards and allowing the realization of flexible functional thin layers. The most important synthesis techniques, functional properties, and practical applications have been reviewed in the present manuscript.

\section{Disclosure}

$\mathrm{AC}$ was the founder of the company Politronica Inkjet Printing SRL, which is involved in printed electronics; his studies are at the basis of some of the products patented and commercialized by the company. AC and SB are shareholders of the same Politronica. The other authors report no conflicts of interest in this work.

\section{References}

1. Samarasinghe SR, Pastoriza-Santos I, Edirisinghe MJ, et al. Electric-jet assisted layer-by-layer deposition of gold nanoparticles to prepare conducting tracks. Nat Sci. 2009;1(2):142-150.

2. Abhinav VK, Rao VR, Karthik PS, Singh SP. Copper conductive inks: synthesis and utilization in flexible electronics. RSC Adv. 2015;46(39): 63985-64030.

3. Pudas M, Halonen N, Granat P, Vähäkangas J. Gravure printing of conductive particulate polymer inks on flexible substrates. Prog Org Coat. 2005;54(4):310-316.

4. Li D, Sutton D, Burgess A, Graham D, Calvert PD. Conductive copper and nickel lines via reactive inkjet printing. JMater Chem. 2009;19(22): 3719-3724.

5. Lewis HJ, Ryan A. Using electrically conductive inks and adhesives as a means to satisfy European PCB manufacturing directives. JAdhes Sci Technol. 2008;22(8-9):893-913.

6. Fouts RW, AN, Miller BE, Gotcher AJ, inventors; Raychem Corporation, assignee. Conductive polymer compositions and devices. United States patent US 4545926 A. 1985 Oct 8.

7. Xia HS, Wang Q. Ultrasonic irradiation: a novel approach to prepare conductive polyaniline/nanocrystalline titanium oxide composites. Chem Mater. 2002;14(5):2158-2165.

8. Shah VG, Hayes DJ. Trimming and printing of embedded resistors using demand-mode ink-jet technology and conductive polymer. 2002 Available from: http://www.microfab.com/images/papers/IPC_02.pdf. Accessed November 24, 2015.

9. Jeong SH, Woo KH, Kim DJ, et al. Controlling the thickness of the surface oxide layer on $\mathrm{Cu}$ nanoparticles for the fabrication of conductive structures by ink-jet printing. Adv Funct Mater. 2008;18(5):679-686.

10. Huang L, Huang Y, Liang JJ, Wan XJ, Chen YS. Graphene-based conducting inks for direct inkjet printing of flexible conductive patterns and their applications in electric circuits and chemical sensors. Nano Res. 2011;4(7):675-684.

11. Jain PK, Huang X, Sayed IH, Sayed MA. Review of some interesting surface plasmon resonance-enhanced properties of noble metal nanoparticles and their applications to biosystems. Plasmonics. 2007;2(3): $107-118$.

12. Willets KA, Duyne RP. Localized surface plasmon resonance spectroscopy and sensing. Annu Rev Phys Chem. 2007;58(10):267-297.

13. Qi WH, Wang MP. Size and shape dependent melting temperature of metallic nanoparticles. Materials Chemistry and Physics. 2004;88(2-3): 280-284. 
14. Simonelli G. Inchiostro. 1933. Available from: http://www.treccani.it/ enciclopedia/inchiostro_(Enciclopedia-Italiana). Accessed November 16, 2015.

15. Meng XK, Tang SC, Vongehr S. A review on diverse silver nanostructures. J Mater Sci Technol. 2010;26(6):487-522.

16. Wiley B, Sun Y, Mayers B, Xia Y. Shape-controlled synthesis of metal nanostructures: the case of silver. Chemistry. 2005;11(2):454-463.

17. Jain PK, Huang X, El-Sayed IH, El-Sayed MA. Noble metals on the nanoscale: optical and photothermal properties and some applications in imaging, sensing, biology, and medicine. Acc Chem Res. 2008;41(12): $1578-1586$.

18. Shen XS, Wang GZ, Hong X, Zhu W. Nanospheres of silver nanoparticles: agglomeration, surface morphology control and application as SERS substrates. Phys Chem Chem Phys. 2009;11(34):7450-7454.

19. Maier SA, Brongersma ML, Kik PG, Meltzer S, Requicha AA, Atwater HA. Plasmonics - a route to nanoscale optical devices. Adv Mater. 2001;13(19):1501-1505.

20. Avasthi DK, Mishra YK, Kabiraj D, Lalla NP, Pivin JC. Synthesis of metal-polymer nanocomposite for optical applications. Nanotechnology. 2007;18(12):125604.

21. Mishra YK, Mohapatra S, Chakravadhanula VS, et al. Synthesis and characterization of Ag-polymer nanocomposites. J Nanosci Nanotechnol. 2010;10(4):2833-2837.

22. Sau TK, Rogach AL, Jäckel F, Klar TA, Feldmann J. Properties and applications of colloidal nonspherical noble metal nanoparticles. Adv Mater. 2010;22(16):1805-1825.

23. Li X, Zhang F. "Wet" chemical synthesis and manipulation of upconversion nanoparticles. In: Lockwood DJ, editor. Photon Upconversion Nanomaterials. Heidelberg: Springer; 2015:21-71.

24. Iravani S. Green synthesis of metal nanoparticles using plants. Green Chem. 2011;13(10):2638-2650.

25. Guzmán MG, Dille J, Godet S. Synthesis of silver nanoparticles by chemical reduction method and their antibacterial activity. Int $J$ Chem Biomol Eng. 2009;2(3):105-111.

26. Chou KS, Ren CY. Synthesis of nanosized silver particles by chemical reduction method. Mater Chem Phys. 2000;64(3):241-246.

27. Liu YC, Lin LH. New pathway for the synthesis of ultrafine silver nanoparticles from bulk silver substrates in aqueous solutions by sonoelectrochemical methods. Electrochem Commun. 2004;6(11):1163-1168.

28. Sandmann G, Dietz H, Plieth W. Preparation of silver nanoparticles on ITO surfaces by a double-pulse method. J Electroanal Chem (Lausanne). 2000;491(1-2):78-86.

29. Mallick K, Witcomb MJ, Scurrell MS. Self-assembly of silver nanoparticles in a polymer solvent: formation of a nanochain through nanoscale soldering. Mater Chem Phys. 2005;90(2-3):221-224.

30. Zhu J, Liu S, Palchik O, Koltypin Y, Gedanken A. Shape-controlled synthesis of silver nanoparticles by pulse sonoelectrochemical methods. Langmuir. 2000;16(16):6396-6399.

31. Dong C, Zhang X, Cai H, Cao C. Facile and one-step synthesis of monodisperse silver nanoparticles using gum acacia in aqueous solution. J Mol Liq. 2014;196:135-141.

32. Domènech $\mathrm{B}$, Bastos-Arrieta J, Alonso $\mathrm{A}$, Macanás J, Muñoz M, Muraviev DN. Bifunctional polymer-metal nanocomposite ion exchange materials. In: Kilislioglu A, editor. Ion Exchange Technologies. Rijeka, Croatia: InTech; 2012.

33. Xia Y, Xiong Y, Lim B, Skrabalak SE. Shape-controlled synthesis of metal nanocrystals: simple chemistry meets complex physics? Angew Chem Int Ed Engl. 2009;48(1):60-103.

34. Auer S, Frenkel D. Prediction of absolute crystal-nucleation rate in hard-sphere colloids. Nature. 2001;409(6823):1020-1023.

35. LaMer VK, Dinegar RH. Theory, production and mechanism of formation of monodispersed hydrosols. J Am Chem Soc. 1950;72(11): 4847-4854.

36. Matijević E. Controlled colloid formation. Curr Opin Colloid Interface Sci. 1996;1(2):176-183.

37. Schön G, Simon U. A fascinating new field in colloid science: small ligand-stabilized metal clusters and possible application in microelectronics. Colloid Polym Sci. 1995;273(2):101-117.
38. Weller H. Colloidal semiconductor Q-particles: chemistry in the transition region between solid state and molecules. Angew Chem Int Ed Engl. 1993;32(1):41-53.

39. Murray CB, Kagan CR, Bawendi MG. Self-organization of CdSe nanocrystallites into three-dimensional quantum dot superlattices. Science. 1995;270(5240):1335-1338.

40. Tao AR, Habas S, Yang PD. Shape control of colloidal metal nanocrystals. Small. 2008;4(3):310-325.

41. Sun Y, Mayers B, Herricks T, Xia Y. Polyol synthesis of uniform silver nanowires: a plausible growth mechanism and the supporting evidence. Nano Lett. 2003;3(7):955-960.

42. Wiley BJ, Chen Y, McLellan J, et al. Synthesis and optical properties of silver nanobars and nanorice. Nano Lett. 2007;7(4):1032-1036.

43. Washio I, Xiong Y, Yin Y, Xia Y. Reduction by the end groups of poly(vinyl pyrrolidone): a new and versatile route to the kinetically controlled synthesis of Ag triangular nanoplates. Adv Mater. 2006;18(13):1745-1749.

44. Xiong Y, Washio I, Chen J, Cai H, Li ZY, Xia Y. Poly(vinyl pyrrolidone): a dual functional reductant and stabilizer for the facile synthesis of noble metal nanoplates in aqueous solutions. Langmuir. 2006;22(20): $8563-8570$.

45. Zeng J, Zheng Y, Rycenga M, et al. Controlling the shapes of silver nanocrystals with different capping agents. J Am Chem Soc. 2010;132(25):8552-8553.

46. Barbieri A, Accorsi G, Armaroli N. Luminescent complexes beyond the platinum group: the $\mathrm{d}^{10}$ avenue. Chem Commun (Camb). 2008;(19): 2185-2193.

47. Hada H, Yonezawa Y, Yoshida A, Kurakake A. Photoreduction of silver ion in aqueous and alcoholic solutions. J Phys Chem. 1976;80(25): 2728-2731.

48. Sato T, Onaka H, Yonezawa Y. Sensitized photoreduction of silver ions in the presence of acetophenone. J Photochem Photobiol A Chem. $1999 ; 127(1-3): 83-87$.

49. Itakura T, Torigoe K, Esumi K. Preparation and characterization of ultrafine metal particles in ethanol by UV irradiation using a photoinitiator. Langmuir. 1995;11(10):4129-4134.

50. Esumi K, Matsumoto T, Seto Y, Yoshimura T. Preparation of gold-, gold/ silver-dendrimer nanocomposites in the presence of benzoin in ethanol by UV irradiation. J Colloid Interface Sci. 2005;284(1):199-203.

51. Scaiano JC, Billone P, Gonzalez CM, et al. Photochemical routes to silver and gold nanoparticles. Pure Appl Chem. 2009;81(4):635-647.

52. Courrol LC, de Oliveira Silva FR, Gomes L. A simple method to synthesize silver nanoparticles by photo-reduction. Colloids Surf A Physicochem Eng Asp. 2007;305(1-3):54-57.

53. Yang S, Wang Y, Wang Q, Zhang R, Ding B. UV irradiation induced formation of Au nanoparticles at room temperature: the case of $\mathrm{pH}$ values. Colloids Surf A Physicochem Eng Asp. 2007;301(1-3):174-183.

54. Han MY, Quek CH. Photochemical synthesis in formamide and room-temperature Coulomb staircase behavior of size-controlled gold nanoparticles. Langmuir. 2000;16(2):362-367.

55. Scaiano JC, Aliaga C, Maguire S, Wang D. Magnetic field control of photoinduced silver nanoparticle formation. J Phys Chem B. 2006;110(26):12856-12859.

56. Hada H, Yonezawa Y, Saikawa M. Photoreduction of silver in a titanium dioxide suspension. Bull Chem Soc Jpn. 1982;55(7):2010-2014.

57. Yonezawa Y, Kometani N, Sakaue T, Yano A. Photoreduction of silver ions in a colloidal titanium dioxide suspension. J Photochem Photobiol A Chem. 2005;171(1):1-8.

58. Zhang H, Wang G, Chen D, Lv X, Li J. Tuning photoelectrochemical performances of $\mathrm{Ag}-\mathrm{TiO}_{2}$ nanocomposites via reduction/oxidation of Ag. Chem Mater. 2008;20(20):6543-6549.

59. Hada H, Tanemura H, Yonezawa Y. Photoreduction of the silver ion in a zinc oxide suspension. Bull Chem Soc Jpn. 1978;51(11): 3154-3160.

60. Tung HT, Chen IG, Kempson IM, et al. Shape-controlled synthesis of silver nanocrystals by X-ray irradiation for inkjet printing. ACS Appl Mater Interfaces. 2012;4(11):5930-5935. 
61. Jeong S, Song HC, Lee WW, Choi Y, Riu BH. Preparation of aqueous Ag ink with long-term dispersion stability and its inkjet printing for fabricating conductive tracks on a polyimide film. J Appl Phys. 2010;108(10):102805.

62. Park SK, Kim YH, Han JI. High-resolution patterned nanoparticulate Ag electrodes toward all printed organic thin film transistors. Org Electron. 2009;10(6):1102-1108.

63. Aggarwal R, Narayan RJ, Xiao K, Geohegan DB. Fabrication of Agtetracyanoquinodimethane nanostructures using ink-jet printing/vaporsolid chemical reaction process. J Vac Sci Technol B Microelectron Nanometer Struct Process Meas Phenom. 2008;26(6):L48.

64. Perelaer J, De Gans BJ, Schubert US. Ink-jet printing and microwave sintering of conductive silver tracks. Adv Mater. 2006;18(16): 2101-2104.

65. Ko SH, Pan H, Grigoropoulos C, Luscombe CK, Frechet JM, Poulikakos D. Air stable high resolution organic transistors by selective laser sintering of ink-jet printed metal nanoparticles. Appl Phys Lett. 2007;90(14):141103-141105.

66. Bai JG, Creehan KD, Kuhn HA. Inkjet printable nanosilver suspensions for enhanced sintering quality in rapid manufacturing. Nanotechnology. 2007;18(18):185701.

67. Reinnhold I, Hendriks CE, Eckardt R, et al. Argon plasma sintering of inkjet printed silver tracks on polymer substrates. J Mater Chem. 2009;19(21):3384-3388.

68. Allen M, Alastalo A, Suhonen M, Mattila T, Leppäniemi J, Seppä H Contactless electrical sintering of silver nanoparticles on flexible substrates. IEEE Trans Microw Theory Tech. 2011;59(5): 1419-1429.

69. Magdassi S, Grouchko M, Berezin O, Kamyshny A. Triggering the sintering of silver nanoparticles at room temperature. ACS Nano. 2010;4(4):1943-1948.

70. Greer JR, Street RA. Thermal cure effects on electrical performance of nanoparticle silver inks. Acta Mater. 2007;55(18): 6345-6349.

71. Fuller S, Wilhelm EJ, Jacobson JM. Ink-jet printed nanoparticle microelectromechanical systems. J Microelectromech Syst. 2002;11(1): 54-60.

72. Lee HH, Chou KS, Huang KC. Inkjet printing of nanosized silver colloids. Nanotechnology. 2005;16(10):2436-2441.

73. Chiolerio A, Cotto M, Pandolfi P, et al. Ag nanoparticle-based inkjet printed planar transmission lines for RF and microwave applications: considerations on ink composition, nanoparticle size distribution and sintering time. Microelectron Eng. 2012;97(9):8-15.

74. Jeevika A, Shankaran DR. Seed-free synthesis of $1 D$ silver nanowires ink using clove oil (Syzygium aromaticum) at room temperature. J Colloid Interface Sci. 2015;458:155-159.

75. Finn DJ, Lotya M, Coleman JN. Inkjet printing of silver nanowire networks. ACS Appl Mater Interfaces. 2015;7(17):9254-9261.

76. Lee YI, Kim S, Jung SB, Myung NV, Choa YH. Enhanced electrical and mechanical properties of silver nanoplatelet-based conductive features direct printed on a flexible substrate. ACS Appl Mater Interfaces. 2013;5(13):5908-5913.

77. Lee CL, Chang KC, Syu CM. Silver nanoplates as inkjet ink particles for metallization at a low baking temperature of $100^{\circ} \mathrm{C}$. Colloids Surf A Physicochem Eng Asp. 2011;381(1-3):85-91.

78. Rapp L, Ailuno J, Alloncle AP, Delaporte P. Pulsed-laser printing of silver nanoparticles ink: control of morphological properties. Opt Express. 2011;19(22):21563-21574.

79. Henry AI, Bingham JM, Ringe E, Marks LD, Schatz GC, Van Duyne RP. Correlated structure and optical property studies of plasmonic nanoparticles. J Phys Chem C Nanomater Interfaces. 2011;115(19):9291-9305.

80. Mao P, Chen J, Xu R, et al. Self-assembled silver nanoparticles: correlation between structural and surface plasmon resonance properties. Appl Phys A Mater Sci Process. 2014;117(3):1067-1073.

81. Mishra YK, Adelung R, Kumar G, et al. Formation of self-organized silver nanocup-type structures and their plasmonic absorption. Plasmonics. 2013;8(2):811-815.
82. Kumar M, Suchand SC, Kumar G, Mishra YK, Philip R, Reddy GB. Plasmonic and nonlinear optical absorption properties of Ag: $\mathrm{ZrO}_{2}$ nanocomposite thin films. Plasmonics. 2014;9(1):129-136.

83. Hyun M. Long-range surface plasmon polariton waveguides containing very thin spin-coated silver films. Thin Solid Films. 2011;519(18):6097-6101.

84. Xiong Z, Dong C, Cai H, Liu C, Zhang X. Composite inks of poly(3,4ethylenedioxythiophene)/poly(styrenesulfonate)/silver nanoparticles and electrical/optical properties of inkjet-printed thin films. Mater Chem Phys. 2013;141(1):416-422.

85. Park JD, Lim S, Kim H. Patterned silver nanowires using the gravure printing process for flexible applications. Thin Solid Films. 2015;586:70-75.

86. Yeo CI, Choi JH, Kim JB, Lee JC, Lee YT. Spin-coated Ag nanoparticles for enhancing light absorption of thin film a-Si:H solar cells. Opt Mater Express. 2014;4(2):346-351.

87. Krantz J, Forberich K, Kubis P, et al. Printing high performance reflective electrodes for organic solar cells. Org Electron. 2015;17: 334-339.

88. Xia Y, Halas NJ. Shape-controlled synthesis and surface plasmonic properties of metallic nanostructures. MRS Bull. 2005;30(5): 338-348.

89. Haynes CL, McFarland AD, Van Duyne RP. Surface-enhanced Raman spectroscopy. Anal Chem. 2005;77(17):338-346.

90. Jeanmaire DL, Van Duyne RP. Surface Raman spectroelectrochemistry: Part I. Heterocyclic, aromatic, and aliphatic amines adsorbed on the anodized silver electrode. J Electroanal Chem. 1977;84(1):1-20.

91. Fleischmann M, Hendra PJ, McQuillan AJ. Raman spectra of pyridine adsorbed at a silver electrode. Chem Phys Lett. 1974;26(2):163-166.

92. Mishra YK, Mohapatra S, Kabiraj D, et al. Synthesis and characterization of Ag nanoparticles in silica matrix by atom beam sputtering. $\mathrm{Scr}$ Mater. 2007;56(7):629-632.

93. Singhal R, Agarwal DC, Mohapatra S, et al. Synthesis and characterizations of silver-fullerene C70 nanocomposite. Appl Phys Lett. 2008;93(10):103114-103116.

94. Singhal R, Agarwal DC, Mishra YK, et al. Electronic excitation induced tuning of surface plasmon resonance of Ag nanoparticles in fullerene C70 matrix. J Phys D Appl Phys. 2009;42(15):155103.

95. Virga A, Rivolo P, Descrovi E, et al. SERS active Ag nanoparticles in mesoporous silicon: detection of organic molecules and peptideantibody assays. J Raman Spectrosc. 2012;43(6):730-736.

96. Chiolerio A, Virga A, Pandolfi P, et al. Direct patterning of silver particles on porous silicon by inkjet printing of a silver salt via in-situ reduction. Nanoscale Res Lett. 2012;7(1):502-508.

97. Kumar PS, Pastoriza-Santos I, Rodríguez-González B, de Abajo FJ, Liz-Marzán LM. High-yield synthesis and optical response of gold nanostars. Nanotechnology. 2008;19(1):015606.

98. Rybak A, Boiteux G, Melis F, Seytre G. Conductive polymer composites based on metallic nanofiller as smart materials for current limiting devices. Compos Sci Technol. 2010;70(2):410-416.

99. Kim WT, Jung JH, Kim TW, Son DI. Current bistability and carrier transport mechanisms of organic bistable devices based on hybrid Ag nanoparticle-polymethyl methacrylate polymer nanocomposites. Appl Phys Lett. 2010;96(25):253301-253303.

100. Mahendia S, Tomar AK, Kumar S. Electrical conductivity and dielectric spectroscopic studies of PVA-Ag nanocomposite films. J Alloys Compd. 2010;508(2):406-411.

101. Gautam A, Ram S. Preparation and thermomechanical properties of Ag-PVA nanocomposite films. Mater Chem Phys. 2010;119(1-2): 266-271.

102. Zhang R, Moon KS, Lin W, Wong CP. Preparation of highly conductive polymer nanocomposites by low temperature sintering of silver nanoparticles. J Mater Chem. 2010;20(10):2018-2023.

103. Chun KY, Oh Y, Rho J, et al. Highly conductive, printable and stretchable composite films of carbon nanotubes and silver. Nat Nanotechnol. 2010;5(12):853-857.

104. Pudas M, Hagberg J, Leppävuori S. Gravure offset printing of polymer inks for conductors. Prog Org Coat. 2004;49(4):324-335. 
105. Nambiar S, Yeow JT. Conductive polymer-based sensors for biomedical applications. Biosens Bioelectron. 2011;26(5):1825-1832.

106. Chiolerio A, Sangermano M. In situ synthesis of Ag-acrylic nanocomposites: tomography-based percolation model, irreversible photoinduced electromigration and reversible electromigration. Mater Sci Eng B Solid State Mater Adv Technol. 2012;177(4):373-380.

107. Sangermano M, Roppolo I, Camara VH, et al. Polysulfone/metal nanocomposites by simultaneous photoinduced crosslinking and redox reaction. Macromol Mater Eng. 2011;296(9):820-825.

108. Chiolerio A, Vescovo L, Sangermano M. Conductive UV-cured acrylic inks for resistor fabrication: Models for their electrical properties. Macromol Chem Phys. 2010;211(18):2008-2016.

109. Sangermano M, Yagci Y, Rizza G. In situ synthesis of silver-epoxy nanocomposites by photoinduced electron transfer and cationic polymerization processes. Macromolecules. 2007;40(25):8827-8829.

110. Vescovo L, Sangermano M, Scarazzini R, Kortaberria G, Mondragon I. In-situ-synthetized silver/epoxy nanocomposites: electrical characterization by means of dielectric spectroscopy. Macromol Chem Phys. 2010;211(17):1933-1939.

111. Colucci G, Celasco E, Mollea C, Bosco F, Conzatti L, Sangermano M. Hybrid coatings containing silver nanoparticles generated in situ in a thiol-ene photocurable system. Macromol Mater Eng. 2011;296(10):921-928.

112. Cook WD, Nghiem QD, Chen Q, Chen F, Sangermano M. Simultaneous photoinduced silver nanoparticles formation and cationic polymerization of divinyl ethers. Macromolecules. 2011;44(11):4065-4071.

113. Chiolerio A, Roppolo I, Sangermano M. Radical diffusion engineering: tailored nanocomposite materials for piezoresistive inkjet printed strain measurement. RSC Adv. 2013;3(10):3446-3452.

114. Nair JR, Ijeri VS, Gerbaldi C, Bodoardo S, Bongiovanni R, Penazzi N. Novel self-directed dual surface metallisation via UVcuring technique for flexible polymeric capacitors. Org Electron. 2010;11(11):1802-1808.

115. Trandafilović LV, Luyt AS, Bibić N, et al. Formation of nano-plate silver particles in the presence of polyampholyte copolymer. Colloids Surf A Physicochem Eng Asp. 2012;414:17-25.

116. Govindaraju A, Chakraborty A, Luo C. Reinforcement of PDMS masters using SU-8 truss structures. J Micromech Microeng. 2005;15(6):1303-1309.

117. Mannsfeld SC, Tee BC, Stoltenberg RM, et al. Highly sensitive flexible pressure sensors with microstructured rubber dielectric layers. Nat Mater. 2010;9(10):859-864.

118. Harsaanyi G. Polymer films in sensor applications: a review of present uses and future possibilities. Sens Rev. 2000;20(2):98-105.

119. Shimojo M, Namiki A, Ishikawa M, Makino R, Mabuchi K. A tactile sensor sheet using pressure conductive rubber with electrical-wires stitched method. IEEE Sens J. 2004;4(5):589-596.

120. Strümpler R, Glatz-Reichenbach J. Conducting polymer composites. J Electroceram. 1999;3(4):329-346.

121. Fu SY, Feng XQ, Lauke B, Mai YW. Effects of particle size, particle/matrix interface adhesion and particle loading on mechanical properties of particulate-polymer composites. Compos Part B Eng. 2008;39(6):933-961

122. Toker D, Azulay D, Shimoni N, Balberg I, Millo O. Tunneling and percolation in metal-insulator composite materials. Phys Rev B Condens Matter Mater Phys. 2003;68(4):041403.

123. Lundberg B, Sundqvist B. Resistivity of a composite conducting polymer as a function of temperature, pressure, and environment: applications as a pressure and gas concentration transducer. $J$ Appl Phys. 1986;60(3):1074-1079.
124. Lantada AD, Lafont P, Sanz JL, Munoz-Guijosa JM, Otero JE. Quantum tunnelling composites: characterisation and modelling to promote their applications as sensors. Sensor Actuat A Phys. 2010;164(1-2):46-57.

125. Zhang XW, Zheng PY, Yi XQ. Time dependence of piezoresistance for the conductor-filled polymer composites. J Polym Sci B Polym Phys. 2000;38(21):2739-2749.

126. Bloor D, Donnelly K, Hands PJ, Laughlin P, Lussey D. A metalpolymer composite with unusual properties. J Phys D Appl Phys. 2005;38(16):2851-2860.

127. Hong L, Li Q, Lin H, Li Y. Synthesis of flower-like silver nanoarchitectures at room temperature. Mater Res Bull. 2009;44(6):1201-1204.

128. Molesa S, Redinger DR, Huang DC, Subramanian V. High-quality inkjet-printed multilevel interconnects and inductive components on plastic for ultra-low-cost RFID applications. MRS Proc. 2003;769: H831-H836.

129. Magdassi S, Bassa A, Vinetsky Y, Kamyshny A. Silver nanoparticles as pigments for water-based ink-jet inks. Chem Mater. 2003;15(11): 2208-2217.

130. Bidoki SM, Lewis DM, Clark M, Vakorov A, Millner PA, McGorman D. Ink-jet fabrication of electronic components. J Micromech Microeng. 2007;17(5):967-974.

131. Tiberto P, Barrera G, Celegato F, et al. Magnetic properties of jetprinter inks containing dispersed magnetite nanoparticles. Eur Phys J B. 2013;86(4):173-178.

132. Soltman D, Subramanian V. Inkjet-printed line morphologies and temperature control of the coffee ring effect. Langmuir. 2008;24(5): 2224-2231.

133. Lichtenberger M. Inks - water-based. 2004. Available from: http:// davidlu.net/Matt.pdf. Accessed November 24, 2015.

134. Chiolerio A, Maccioni G, Martino P, et al. Inkjet printing and low power laser annealing of silver nanoparticle traces for the realization of low resistivity lines for flexible electronics. Microelectron Eng. 2011;88(8):2481-2483.

135. Kamyshny S, Steinke J, Magdassi S. Metal-based inkjet inks for printed electronics. Open Appl Phys J. 2011;411(19):19-36.

136. Li H, Fu C, Xu J. Topography of thin film formed by drying silver nanoparticle dispersion droplets. Jpn J Appl Phys. 2007;46(10A): 6807-6810.

137. van Osch TH, Perelaer J, Laat AW, Schubert US. Inkjet printing of narrow conductive tracks on untreated polymeric substrates. Adv Mater. 2008;20(2):343-345.

138. Meier H, Loeffelmann U, Mager D, Smith PJ, Korvink JG. Inkjet printed, conductive, $25 \mu \mathrm{m}$ wide silver tracks on unstructured polyimide. Phys Status Solidi A Appl Mater Sci. 2009;206(7):1626-1630.

139. Singh M, Haverinen HM, Dhagat P, Jabbour GE. Inkjet printing process and its applications. Adv Mater. 2010;22(6):673-685

140. Rao VK, Abhinav VK, Karthik PS, Singh SP. Conductive silver inks and their applications in printed and flexible technologies. RSC $A d v$. 2015;5(95):77760-77790.

141. Krebs FC. Pad printing as a film forming technique for polymer solar cells. Sol Energy Mater Sol Cells. 2009;93(4):484-490.

142. Fleming WJ. Overview of automotive sensor. IEEE Sens J. 2001; 1(4):296-308.

143. Fleming WJ. New automotive sensors - a review. IEEE Sens J. 2008; 8(11):1900-1921.

144. Hrehorova E, Rebros M, Pekarovicova A, et al. Gravure printing of conductive inks on glass substrates for applications in printed electronics. J Disp Technol. 2011;7(6):318-324. 


\section{Publish your work in this journal}

Nanotechnology, Science and Applications is an international, peer-reviewed, open access journal that focuses on the science of nanotechnology in a wide range of industrial and academic applications. It is characterized by the rapid reporting across all sectors, including engineering, optics, bio-medicine, cosmetics, textiles, resource sustainability and science. Applied research into nano-materials, particles, nano-structures and fabrication, diagnostics and analytics, drug delivery and toxicology constitute the primary direction of the journal. The manuscript management system is completely online and includes a very quick and fair peer-review system, which is all easy to use. Visit http://www.dovepress.com/ testimonials.php to read real quotes from published authors.

Submit your manuscript here: http://www.dovepress.com/nanotechnology-science-and-applications-journal 